Derleme

Kardeş İstismarı

\title{
Kardeş İstismarı: Tanımı, Nedenleri ve Kardeş İlişkisi ile Kardeş İstismarının Ayrılan Yönleri
}

\author{
Esra Işık ${ }^{1}$ Zeynep Çetin ${ }^{1}$
}

${ }^{1}$ Hacettepe Üniversitesi Sağlık Bilimleri Fakültesi Çocuk Gelişimi Bölümü

\begin{abstract}
Özet
Toplumda aile ortamının güvenli bir yer olduğu ile ilgili yaygın bir görüş bulunmasına rağmen, aile ortamı bazen şiddetin ve istismarın meydana geldiği bir ortam haline gelebilmektedir. Literatür incelendiğinde aile içi istismarla ilgili çalışmalar yapılmış olmasına karşın, kardeş istismarı diğer aile istismarları ile ilgili yapılan çalışmaların gerisinde kalmıştır. Bu makalede kardeş istismarına değinilmektedir. Makalenin amacı kardeş istismarını, kardeş istismarına neden olan faktörleri tanımlamak ve kardeş ilişkisi ile kardeş istismarı arasındaki farka değinerek konu ile ilgili farkındalığı artırmaktır.
\end{abstract}

Anahtar Kelimeler: Kardeş istismarı, kardeş ilişkisi

Sorumlu Yazar: Esra Işık. Hacettepe Üniversitesi, Sağlık Bilimleri Fakültesi, Çocuk Gelişimi Bölümü. 0312 30515 26. esra.isik@ hacettepe.edu.tr

*Bu makale yüksek lisans tezinden üretilmiştir. 


\title{
Sibling Abuse: Definition, Causes and Differences between Sibling Relationship with Sibling Abuse
}

\author{
Esra Iş1k ${ }^{1}$, Zeynep Çetin ${ }^{1}$ \\ ${ }^{1}$ Hacettepe University, Faculty of Health Sciences, Department of Child Development
}

\begin{abstract}
Although there is a common opinion in society that the family environment is a safe place, sometimes it can become an environment where violence and abuse occurred. When the literature is reviewed, although studies have been made about domestic abuse, sibling abuse had remained behind other studies which related the other domestic abuse. Sibling abuse are mentioned in this article. The purpose of this article is to definition sibling abuse, the factors that cause sibling abuse and is intented to increase awareness on the subject referring to the difference between the sibling relationship with the sibling abuse.
\end{abstract}

Keywords: Sibling abuse, sibling relationship.

Corresponding Author: Esra Işık. Hacettepe Üniversitesi, Sağllk Bilimleri Fakültesi, Çocuk Gelişimi Bölümü. 031230515 26. esra.isik@ hacettepe.edu.tr

*This article is made from a master thesis. 


\section{Giriş}

\section{Kardeș İstismarının Tanımı}

Aile içi şiddet bireyin yaşamını pek çok açıdan olumsuz yönde etkileyebilecek istismarın yaygın bir biçimidir (Evans, Davies ve DiLillo, 2008). Şiddet davranışı, diğer ilişkilerde olduğu gibi kardeşler arasındaki ilişkilerin de bozulmasına neden olan ve aile denklemi içerisindeki olumsuz değişkenleri gösteren bir unsurdur (Conger, Stocker ve McGuire, 2009; Dunn ve Davies, 2001; Kiselica ve Morrill-Richards, 2007).

Çocukların tanık oldukları süreğen aile şiddetinde, ebeveynler istemeden çocuklarına saldırganlık modeli olabilmekte ve çocuklar şiddeti kardeşleri ile aralarındaki çatışmayı çözmek için kabul edilebilir bir yol olarak yorumlayabilmektedirler (Noller, 2005; Orue, Bushman, Calvete, Thomaes, De Castro ve Hutteman, 2011).

Aile istismarı, istismarın oldukça önemli ve yaygın bir türü olmasına rağmen, aile içi istismar kapsamında kardeş istismarı büyük ölçüde fark edilmeden kalmış veya göz ardı edilmiştir.

Kardeş istismarı bir kardeşin başka bir kardeş tarafından fiziksel, duygusal ve cinsel yönden istismarıdır (Wiehe, 1997). Çocukların sürekli olarak aynı evde birlikte yaşadıkları ve birlikte büyüdükleri düşünüldüğünde, herhangi bir ailede kardeşler arasında istismar olabilmesi mümkündür. İstismarın tek bir türü kendi başına olabileceği gibi genellikle çeşitli türleri de (fiziksel, duygusal ve cinsel) birbirleri ile etkileşim içinde meydana gelebilir.

Bazı aileler kardeşler arasındaki istismarı görmezlikten gelmekte ya da çocukları neler olup bittiğini anlattığında, çocuklarına inanmamaktadırlar. Bazı aileler ise kardeş istismarının normal bir davranış olduğunu ve sadece büyümenin normal bir parçası olan kardeş rekabeti olduğunu söylemektedirler (Wiehe,1997).

\section{Kardeş İstismarına Neden Olan Faktörler}

Bazı araştırmacılar kardeş istismarının oluşumunda Bir takım faktörlerin önemli rol oynadığını ve kardeş istismarı oluşma riskini artırdığını belirtmişlerdir. Kardeş istismarına neden olan çok sayıda faktör bulunmaktadır. Bunlar kardeş istismarının meydana gelme nedenlerini anlama konusunda yardımcı olmaktadır. Bu faktörler; gücün kötüye kullanılması, uygun olmayan beklentiler, küçük kardeşin büyük kardeşin sorumluluğunda olması, ebeveyn davranışını model alma, ebeveynlerin kendi sorunları ile bunalmış olması, fiziksel ve zihinsel hastalıklar, stresle ilgili sorunlar, mağdurun olaylara etkisi, ebeveynlerin etkisiz müdahaleleri, 
istismar edici davranışın normal olarak görülmesi, öfkenin uygun olmayan bir şekilde dışa vurulmas1, televizyon ve videoların etkisidir (Bank ve Kahn, 1982; Leder,1993; akt. Kiselica ve Morrill-Richards, 2007; Wiehe, 1997).

Bunlardan birincisi olan gücün kötüye kullanılması, çocuk, eş ve yetişkin istismarı gibi bütün aile istismarlarının yanı sıra, kardeş istismarının bütün türlerinin de (fiziksel, duygusal ve cinsel) ortak özelliğidir. Gücün kötüye kullanımı, daha güçlü olan bir bireyin daha az güçlü olan bir birey üzerinde gücünün odaklanmasıdır. Kardeş istismarında, bu genellikle büyük kardeşin küçük kardeşi fiziksel ya da duygusal istismar etmesidir (Wiehe, 1997). Gücün kötüye kullanılması güçlünün zayıfa karşı bir eylemi gibi görünüyor olsa da, failin aslında bu istismar edici eylemlerle uğraşmasının nedeni, fail tarafından algılanan eksik ya da düşük gücü telafi etmektir (Finkelhor, 1983).

Uygun olmayan beklentiler, kardeș istismarının meydana gelmesinde etkili olan bir diğer faktördür. Uygunsuz beklentiler çoğunlukla yetişkin-çocuk istismarı ile ilişkilidir. Çocuklarını fiziksel olarak istismar eden aileler, genellikle çocuklarının gelişimsel evrelerini eksik anlayan, çocuklarından gerçekçi olmayan beklentileri olan ve çocuklarının yetişkin gibi davranmalarını bekleyen ailelerdir (Bavolek, 1989; Berg, 1976; Clark, 1975; Hawkins ve Duncan, 1985; Kravitz ve Driscoll, 1983; akt. Wiehe, 1997). Bu tür ebeveynler çocukları onların beklentilerini yerine getirmediklerinde, genellikle istismar edici davranışlarda bulunurlar (Wiehe, 1997; Szasz, 1984). Benzer şekilde büyük kardeşlerin denetleyici rolünde iken, genellikle ebeveynlerinden gördükleri, yaşadıkları teknikleri ve istismar edici davranışları taklit etmeleri muhtemeldir (Crittenden, 1982; Green, 1984).

Kardeş istismarının en sık bahsedilen sebebi, genellikle daha küçük olan bir kardeşin daha büyük bir kardeş tarafından istismar edilmesidir ki bu genellikle büyük kardeşin küçük kardeşin bakımından sorumlu olduğu durumlarda meydana gelmektedir. Ebeveynler büyük kardeşin çocuk bakıcılığı sorumluluğunun üstesinden gelebileceğini varsaymakta ve büyük kardeşin istismar edici rolde olabileceğini beklememektedirler. Ĕger büyük kardeş bu sorumluluğun üstesinden gelebiliyorsa, ebeveynlerin evde olmadıkları zamanlarda büyük kardeşi sorumlu kişi olarak bırakmaları uygundur. Büyük kardeşin küçük kardeşe bakmakla sorumlu olduğu durumlarda küçük kardeşten bitmek bilmeyen isteklerde bulunulması kardeş istismarına neden olabilmektedir. Büyük kardeşler küçük kardeşlere isteklerini yaptırmada başarılı olamadıkları zaman, fiziksel ve duygusal istismara başvurabilirler (Wiehe, 1997). Bunun nedenlerinden biri, büyük kardeşin ebeveynlerin davranışlarını model alması olabilir. 
İstismar edici davranış genellikle öğrenilir. Büyük kardeş küçük kardeşinin üzerinde kontrol kurmanın bir yolu olarak istismar edici yöntemleri öğrenmiş olabilir. Fiziksel ve duygusal istismar, ebeveynlerin çocuklarına isteklerini yaptırmak için kullandıkları birincil yol olabilir. (Wiehe, 1997).

Kardeş istismarının meydana gelmesinde bir diğer faktör ise ebeveyn davranışını model almadır. Wiehe (1997) tarafından yapılan araştırmada, kardeş istismarına maruz kalan katılımcılar kardeşlerinden gördükleri fiziksel ve duygusal istismarın, ebeveynlerin birbirlerine olan davranışlarından farksız olduğunu bildirmişlerdir. Bu durum iki şekilde açıklanabilir. İlk olarak, çocuklar ebeveynlerinin davranışları sonrasında onların davranışlarını model alıyor olabilir. Nitekim Wiehe (1997)'nin bir araştırması, ebeveyn şiddetine tanık olan çocukların tanık olmayan çocuklara göre daha çok davranışsal sorunları gösterme eğiliminde olduklarını göstermektedir. İkincisi, kardeş istismarı bu davranışsal problemlerden birinin dişa vurumu olabilir (Hughes, Parkinson ve Vargo, 1989; Jouriles, Barling, ve O'Leary, 1987; Suh ve Abel, 1990; Wiehe, 1997). Sosyal öğrenme kuramı şiddete ve sözel istismara tanıklık eden ve şiddeti ve istismarı yaşayan çocukların kardeşleri ile olan etkileşimlerinde bu davranışları model alma olasılıklarının yüksek olduğunu belirtmektedir (Hoffman, Kiecolt ve Edwards, 2005).

Ebeveyn davranışları da bazı durumlarda istismarı tetikleyen faktörlerden biri haline gelebilmektedir. Dolayısıyla ebeveynler kardeşler arasındaki ilişkilerde dengeyi bozacak tutum ve davranışlardan mümkün olabildiğince sakınmalıdırlar.

Ebeveynlerin kardeşler arasında kayırmacılık yapması ya da kardeşler tarafından o şekilde anlaşılması kardeşler arasındaki saldırganlığın altında yatan temel nedenlerden biri olabilir (Brody, Stoneman ve McCoy, 1994; akt. Tippett ve Wolke, 2015). Ebeveynleri tarafından daha az ilgilenilen çocuk, bu kızgınlığını kardeşlerine yönelik saldırganlık şeklinde ifade edebilir. Bu ifade yöntemi, kardeş ilişkilerinde daha büyük olumsuzluklara yol açan ve kardeşlerin birbirlerine karşı kavgacı tutumlarını artıran davranışlardandır. Ebeveynler tarafindan sürekli olarak evde bir çocuğun tarafının tutulması çocuğu ya da istismar edici davranışın kabul edilmesini pekiştirerek, diğer kardeşleri istismar edici davranışa teşvik edebilmektedir (Meyers, 2014).

Kardeşlerin neden diğer kardeşler tarafından fiziksel ve duygusal istismar edildiğinin diğer bir nedeni de, ebeveynlerin kendi sorunları ile oldukça bunalmış olması ve kardeşler arasında olup bitenlerin farkında olmamalarıdır. Ebeveynlerin bazıları yaşadıkları alkol problemleri, akıl hastalığı ve evlilik problemleri gibi sorunlarla uğraşmakta ve ebeveynlerin yaşadıkları bu problemler kardeş istismarına etkili bir şekilde müdahale etmeye engel 
olabilmektedir (Wiehe, 1997). Dolayısıyla strese neden olan çevresel faktörler meydana geldiğinde, çocuklar ebeveynlerin şiddetine maruz kalabilirler. Kendi sorunlarıyla bunalmış ebeveynlerin çocuklarına gerekli duygusal destek sağlamaları mümkün değildir ve çocuklarının duygu yoğunluğuna tahammül edemeyebilirler. Bu aileler genellikle eleştiri, yargı ve istismar edici iletişimden oluşan olumsuz bir atmosfer yaratır. Ev ortamındaki ilişkilerin bozuk, düzensiz ve ne olacağı önceden belli olmayan koşulların paylaşıldığı ev ortamında, istismar görülme olasılığı yüksektir (Meyers, 2014).

Ailede zihinsel ve fiziksel hastalıkları olan bireyin varlı $\breve{g l}$, kardeş istismarında etkili bir faktör olarak görülebilir. Kronik zihinsel ya da fiziksel hastalık ailenin enerjisini tüketebilir, aile çocuklarını başıboş bırakabilir ya da bakımla sorumlu büyük kardeş bakım rolünü yerine getiremeyebilir (Wiehe, 1997).

Kardeş istismarının meydana gelmesinde bir diğer faktör, stresle ilgili sorunlardır. Ekonomik durumun yeterli olmaması bazen aileleri daha fazla çalışmak zorunda bırakabilmektedir. Yapılan araştırmalarda kardeş istismarına maruz kalan katılımcıların bir kısmı babalarının istismar konusunda ne olduğuyla ilgilenmediğini, çünkü büyük bir aileyi geçindirmek için iki işte çalışmak zorunda olduklarını; diğerleri ise her iki ebeveynin de aileyi geçindirmek için çalışmak zorunda olduklarını, çünkü tek ebeveynin işinin geçim için yeterli olmadığını belirtmişlerdir. Ayrıca ekonomik koşullar aile içerisinde stres oluşturabilmekte ve bu durum da istismarı tetikleyebilmektedir (Whipple ve Finton, 1995; Wiehe, 1997, Hardy, 2001). Yoksulluk içinde yaşayan aileler yetersiz eğitim kaynakları ve yetersiz sağlık hizmetleri ile yüz yüzedirler ve aile içi şiddetin artması riski altındadırlar (Meyers, 2014).

Mağdurun olaylara etkisi kardeş istismarının oluşmasında bir diğer faktördür. Bazı çocuklar onları istismarın hedefi yapan davranışlar geliştirebilirler. Bu gibi durumlarda, istismar çoğu kez döngüsel olur ve giderek artar. Çocuğun davranışları, yetişkinin ya da diğer kardeşin çocuğu daha çok istismar etmesine yol açabilir. Bu da çocuğun davranışını pekiştirerek, daha çok duygusal ve fiziksel istismara maruz kalmasına sebep olabilir. Bazı kardeşler fiziksel özelliklerinden dolayı başka bir kardeşi tarafından istismarın hedefi olur (Wiehe, 1997).

Etkisiz müdahaleler, kardeş istismarının nedenleri arasında sayılabilir. Bazı ailelerde ebeveynler istismara nasıl etkili bir şekilde müdahale edeceklerini ve istismarı nasıl durduracaklarını bilmemektedirler. Bu durum, ebeveynlerin istismar ile ilgilenmedikleri ya da istismar hakkında endişelenmedikleri anlamına gelmemektedir. İstismarı durdurmaya çalıştıkları yol etkili olmamaktadır ve bu yüzden istismar artarak devam etmekte ve bazı durumlarda kontrolden çıkmaktadır. Kardeşler arasında meydana gelen istismar edici 
durumlara ebeveynlerin etkili müdahalede bulunması genellikle davranışı durdurur. $\mathrm{Bu}$ yaklaşım davranışın önlenmesi gerektiği ve ailede tolere edilmeyeceği mesajını verir ve ebeveynlerin etkili müdahalesi davranışın artarak istismara dönüşmesini engeller. Aksine etkisiz müdahaleler ve ebeveynlerin faili dövme gibi bedensel ceza kullanması, istismarı daha çok artırabilir (Hoffman, Kiecolt ve Edwards, 2005; Wiehe, 1997).

Kardeş istismarının meydana gelmesinde bir diğer faktör davranışın normal olarak görülmesidir. Bazı ebeveynler, kardeşler arasındaki fiziksel ve duygusal istismarı normal kabul ederler ve davranışı 'normal kardeş rekabeti' olarak kabul ederler. Kardeş rekabeti normaldir fakat kardeş istismarı değildir. Kardeş rekabeti, kardeşlerimiz etrafımızda olduğu sürece olmuştur. Kardeşlerin ilgilerinin büyük ölçüde ortak olması, kardeş rekabetinde en büyük risktir. Eğer kardeşler ayrılır ve farklı ilgi alanları ve kişilikleri geliştirirlerse, kardeşler arasında bir çatışma olma olasılığı azalır. Kardeşler arasındaki rekabet şiddetli olduğunda istismara dönüşebilir. Kardeş istismarı ve kardeş rekabeti arasında dikkatli bir ayrım yapılmalıdır. Aileler normal kardeş rekabeti ve kardeş istismarı arasında ayrım yapamadığında, bir kardeşin diğerine öfkesini uygunsuz bir şekilde dışa vurumu gibi başka risk faktörlerine yol açabilirler (Kiselica ve Morrill-Richards, 2007; Wiehe, 1997).

Bir kardeşin diğerini istismar etmesindeki başka bir neden öfkenin uygun olmayan bir şekilde dışa vurulmasıdır. Öfkenin dışa vurulması gerektiğini savunanlar, 'stres atmayı' öfkeyle baş etme yolu olarak görmektedirler. $\mathrm{Bu}$ görüşe göre kişinin öfkesini dişa vurması fikri, öfkenin dağıtılmasıdır. Ama asla açığa vurma hedefi kardeşler gibi başka bir kişi olmamalıdır (Berkowitz, 1973; akt. Wiehe, 1997). Fakat bazı araştırmalar öfkenin dışa vurulmasının öfkeyi dağıtmadığını ve aslında çoğu zaman onu şiddetlendirdiği gibi tam tersi bir etkisinin olduğunu göstermektedir. Colorado Üniversitesi'nden psikolog Dr. Seymour Feshbach (1964), saldırgan duygularını açığa vurması için cesaretlendirilen çocukların sonrasında saldırganlık duygularında bir düşüş olmadığını; aksine, öncekinden daha düşmanca ve saldırgan bir şekilde davrandıklarını ifade etmiştir (akt. Wiehe, 1997). Tavris (1982), öfkeye karşı bilişsel yaklaşımı dışa vurumsal yaklaşımdan daha uygun bir yaklaşım olarak görür. Bu yaklaşıma göre; düşünme, duygularını ve öfkelerini açıklama yeteneği insanları hayvanlardan ayıran bir yetenektir. Dolayısıyla bilişsel yaklaşımda, bireyler aralarındaki farklılıklara konuşarak çözüm üretebilirler (akt. Wiehe, 1997). Bilişsel yaklaşım, bireyler kızgın olduğunda onlara bu şekilde hissettiren şeyin ne olduğunu ve tekrar meydana geldiğinde bir sinir çatışmasının nasıl önlenebileceğini göstermektedir (Goleman, 1995; akt. 
Wiehe, 1997). Bu yöntem öfkeyle baş etmede, ‘öfkeyi dışa vurmadan’ ya da fiziksel veya sözel olarak bir insana saldırmaktan çok daha etkili bir yoldur (Wiehe, 1997).

Kardeş istismarının meydana gelmesinde bir diğer faktör ise televizyon ve videoların etkisidir. Çocuklar kardeşlerine karşı kullanmak için öğrendikleri şiddet davranışlarını aileleri dışında farklı yollardan öğrenebilirler. Çocuklar televizyonda, video oyunlarında, filmlerde ve diğer medya araçlarında şiddeti görme ve gördükleri şiddeti benimseme eğilimindedirler (Elliott, Hamburg ve Williams, 1998; Irwin ve Gross, 1995; Lewis, 2005). Araştırmalar televizyonda, videolarda ya da filmlerde görülen istismar edici davranışın failler tarafından model alındığının ya da taklit edildiğinin kısmen açıklanabildiğini göstermektedir. İzleyicilerin sürekli tekrarlanan şiddet içerikli medya programlarına maruz kalması, televizyonda veya filmde gördükleri davranışları model alarak, sonrasında daha çok istismar edici eylemlerde bulunması gibi bir etkiye sahip olduğunu, saldırgan davranışlara teşvik edebildiğini ve medyada uzun süreli şiddete maruz kalmanın izleyiciler üzerinde şiddete yönelik hassasiyet duygusunu azaltıcı yönde bir etkiye sahip olduğunu göstermektedir. Bunun sonucunda izleyiciler şiddete karşı ne olması gerektiği gibi tepki verebilirler, ne de şiddeti artık kaçınılması gereken bir davranış olarak algılayabililer (Eron ve Huesmann, 1985; Leyens, Paik ve Comstock, 1994; akt. Wiehe, 1997). Aynı zamanda araştırmalar şiddet içeren video oyunlarını oynamanın çocukların kişilerarası davranışlarını etkileyebileceğini göstermektedir (Irwin ve Gross, 1995; Lewis, 2005). Araştırmada, çocukların etrafındaki diğer insanlara oyunlarındaki oyun karakterlerinin davrandıkları gibi sözlü ve fiziksel şiddet içeren davranışlar uyguladıklarını bulmuştur. Böyle bir modelleme veya televizyon, video ve filmlerde görülen davranışların taklit edilmesi sonucunda, bu davranışların kardeş ilişkilerinde de ortaya çıkması beklenebilir (Wiehe, 1997). Kısacası medya; taklit etme, duyarsızlaştırma, saldırganlığı uyarma ve risk alma gibi davranışlar yolu ile çocukların davranışlarını etkileyebilmektedir (Lewis, 2005).

Kardeş istismarı, istismara dâhil olan kardeşler haricinde diğer aile bireylerini de kapsamaktadır (Martin Del Campo, 2012). Çok problemli ya da aile düzeni son derece bozuk olan ailelerde kardeş istismarının meydana gelme olasılığı daha yüksek olabilir (Wiehe, 1997). Aile ortamı kardeş istismarı için önemli bir faktördür. Çünkü kardeş istismarı genellikle aile içerisinde tanık olunan ya da yaşanan davranışların bir yansımasıdır (Steinmetz, 1981). 


\section{Kardeş İlişkisi ile Kardeş İstismarının Ayrılan Yönleri}

Kardeş istismarı son derece karmaşıktır ve kolay tanımlanmamıştır. Kardeşler arasındaki normal gelişim davranışının nerede bittiğini ve istismarın nerede başladığını belirlemek zordur. Etkileşimin istismar olup olmadığını belirlerken, kardeş tarafından uygulanan eylemin şiddeti, niyeti ve bu eylemin diğer kardeş üzerindeki duygusal etkisi gibi birçok faktör dikkate alınmalıdır. Kardeş istismarı bir kardeşin diğer kardeşiyle olan ilişkisinde saldırgan olarak rol almasından oluşurken, normal kardeş çatışması genellikle ailenin kaynakları üzerinde olan (örneğin ebeveynin ilgisi) ortak anlaşmazlıkları içermektedir (Johnston ve Freeman, 1989; akt. Kiscelica ve Morril-Richards, 2007). Kardeş rekabeti kardeşler arasında eşit firsatlar yakalamak için meydana gelen avantajlı ya da dezavantajlı davranışları içermektedir (Gelles ve Cornell, 1985). Kardeş istismarı ise sürekli, tutarlı, kasıtlı ve şiddetli eylemlerdir (Wiehe, 1997).

İnsan davranışları çok karmaşıktır ve incelenmesi kolay değildir. Kardeş ilişkilerinde grinin çeşitli tonları bulunabilir ve belirli bir davranışın istismar edici olup olmadığı konusunda sorular sorulmaya her zaman devam edilebilir (Wiehe, 1997).

Bütün kardeşler birbirlerine vurur, tokat atar ve birbirlerini yumruklarlar. Kardeşler normalde birbirlerine lakap takabilirler. O halde kritik olan soru normal kardeş etkileşimleri ile istismar edici davranış arasındaki farktır. Zararlı ve zararsız davranışlar birbirinden nasıl ayırt edebilir? Burada önemli olan istismar eden ya da potansiyel olarak istismar edici olan davranışları normal etkileşimlerden ayırt etmek için kullanılabilecek önemli kriterleri dikkatlice belirlemektir. Ebeveynler, kardeşler arasındaki istismar edici davranışı önemsemeyebilirler, görmezden gelebilirler ve hatta bütün çocukların görünüşte bu davranışlarla meşgul olmalarından dolayı davranışları normal ve hatta zararsız davranışlar olarak algilayabilirler (Wiehe, 1997; Krienert ve Walsh, 2011). Ebeveynler genellikle çocukları arasındaki çatışmalara müdahale etmek yerine görmezden gelebilirler çünkü ebeveynler çoğu tartışmaların ve fiziksel saldırıların bile normal ve zararsız olduğunu varsaymaktadırlar (Hoffman, Kiecolt ve Edwards, 2005). Kardeşler arasında kavga ve kıskançlık olması beklenmesine rağmen, bu davranışlar göz ardı edilmemelidir. İstismar edici olmayan davranış eğer etkili ebeveyn müdahalesi olmazsa istismar edici davranışa dönüşebilir. Davranışı görmezlikten gelmek, onu ortadan kaldırmaz. Kritik soru bu duruma nasıl müdahale edileceğidir (Wiehe, 1997).

Bir davranışın kardeş istismarı olup olmadığını anlamak için yapılması gereken ilk iş davranışı tanımlamaktır. Belirlenen davranış, davranışı çevreleyen öfke, acı ya da utanç gibi 
duygulardan izole edilerek tanımlanmalıdır. $\mathrm{Bu}$ tanımlamada bazı kriterler göz önünde bulundurulmalıdır. İstismar edici davranışı istismar edici olmayan davranıştan ayıran ilk kriter davranışın yaşa uygunluğudur (Wiehe, 1997).

İstismar edici davranışı istismar edici olmayan davranıştan ayıran diğer kriter ise davranışın ne sıklıkta ve ne kadar sürede ortaya çıktığıdır. Kavga etmek, isim takmak ve alay etmek kardeşler arasında meydana gelen ve normal kardeş rekabeti olarak kabul edilebilen davranışlar olmakla birlikte, davranışın sıklığı ve süresi davranışın istismar olup olmadığı ile ilgili fikir verebilir (Wiehe, 1997). Kardeş istismarı kardeş rekabetinden genellikle eylemlerin sürekli, istikrarlı ve şiddetli olması yönünden farklıdır (Hart, Germain ve Brassard, 1987). Kavga etme, isim takma ve alay etme davranışları uzun bir süre içerisinde sık sık meydana geliyorsa ve fail davranışı bırakması konusunda uyarılmasına rağmen davranışı sürdürüyorsa, davranış istismar edici olabilir. Fakat bir davranışın istismar edici olup olmadığının belirlenmesinde tek kriter olarak davranışın sıklığı ve süresi kullanılmamalıdır. Ne kadar uzun süreden kastedilen süre ne kadar uzundur ya da ne kadar sıkl1ktan kastedilen ne kadar sıktır? Sağduyunun kullanılması bu soruları cevaplamak için en iyi yoldur. Bir ebeveyn bir davranışla ilgili rahatsızlık hissetmeye başladığında, o davranışa müdahale zamanı gelmiş demektir (Wiehe,1997).

İstismar edici davranışı normal davranıştan ayırt ederken dikkate alınması gereken bir diğer kriter davranışın amacının ne olduğudur. Bir kardeş tarafindan uygulanan çoğu duygusal istismar durumunda amaç mağdura isim takarak ya da alay ederek mağduru küçümsemektir. Bu zararlı bir davranıştır ve dolayısıyla istismar edicidir (Wiehe, 1997).

Aşağıdaki ek sorular da istismar edici davranışı normal davranıştan ayırt etmede yardımcı olabilir:

- Davranış hangi durumda meydana geldi?

- Davranıştan önce ne oldu?

- Yaşananlar olayda mağdurun olaya katkısı neydi?

- Fail herhangi bir şeyi ya da gördügü bir şeyimi taklit ediyordu?

- Davranış, planlı mıydı yoksa kendiliğinden mi oldu?

- Davranış daha önce de oldu mu?

- Mağdur olanlar hakkında ne hissetti?

- Yaşanan olayla ilgili failin tepkisi ne oldu?

- Fail bu davranışla geçmişte karşılaştı mı? 
Buraya kadar bahsedilen kriterler ve ek sorular istismar edici davranışı normal davranıştan ayırt etmek için tek başına veya birbirleriyle ile bağlantılı olarak kullanılabilir. Bu kriterler 1şı̆̆ında kardeşler arasındaki istismar edici davranışları ve normal davranışları incelemek basit bir konu değildir. Fakat bu kriterler kardeş istismarını değerlendirmek için genel bir yol gösterici olarak işe yarayabilir. Fakat eğer kriterler bir davranışın normal olduğunu gösteriyor ama bir ebeveyn yine de davranış ile ilgili bir rahatsızlık hissediyorsa en güvenilir yaklaşım davranışa potansiyel olarak istismar edici gözüyle bakma ve uygun bir şekilde müdahale etmek olabilir (Wiehe, 1997). Bu anlamda alg1, çocukların büyürken normal gelişimlerinin bir parçası olan kardeş rekabeti ile kardeş istismarının ayırt edilmesinde tanımlayıcı bir rol oynar (Kiselica ve Morrill-Richards, 2007). Kardeş istismarını tanımlamak için algı kavramı da eklenmelidir.

Kardeş ilişkileri ile ilgili literatürde sınırlı kalması nedeniyle çocukluk dönemi kardeş istismarını tanımlamak ve açık bir şekilde nerede normal kardeş çekişmesinin bittiği ve nerede kardeş istismarının başladığını ayırt etmek zor olabilir. Bu nedenle, kardeş ilişkileri ve kardeş istismarı konusunda açıklığa kavuşturma, uzlaşma, farkındalık ve anlayış geliştirme amacıyla daha fazla araştırma yapılması önerilmektedir (Khan ve Cooke, 2013; Morrill ve Bachman, 2013; Skinner ve Kowalski, 2013).

\section{Sonuç ve Öneriler}

İstismar alanında çocuk istismarı ve aile içi şiddet ile ilgili çeşitli çalışmalar yapılmış olmasına rağmen, kardeş istismarı ile ilgili yapılan çalışmaların olmaması dikkat çekicidir. Konu ile ilgili farkındalı̆̆ın artırılması amacıyla kardeş istismarı konusunda başka çalışmaların da yapılması önerilmektedir. 


\section{Kaynakça}

Conger, K. J.,Stocker, C., \&Mcguire, S. (2009). Sibling Socialization: TheEffects of Stressful Life Eventsand Experiences. New Directionsfor Child andAdolescent Development, 2009 (126), 45-59.

Crittenden, P. M. (1984). Sibling İnteraction: Evidence of a GenerationalEffect in Maltreatingİnfants. Child Abuse \&Neglect, 8(4), 433-438.

Elliott, D. S., Hamburg, B. A., \& Williams, K. R. (1998). ViolenceInAmerican Schools: A New Perspective. Cambridge UniversityPress.

Evans, S. E.,Davies, C., \&Dilillo, D. (2008). ExposuretoDomesticViolence: A Meta-Analysis of Child andAdolescentOutcomes. AggressionandViolentBehavior, 13 (2), 131-140.

Finkelhor, D. (1983). CommonFeatures of FamilyAbuse. The Dark Side of Families: CurrentFamilyViolenceResearch, 17-28.

Gelles, R.J. \& Cornell, C.P. (1985). IntimateViolence in Families. ThousandOaks, CA: Sage Publications.

Green, A. H. (1984). Child AbuseBySiblings. Child Abuse \&Neglect, 8 (3), 311-317.

Hardy, M. S. (2001). PhysicalAggressionandSexualBehaviorAmongSiblings: A RetrospectiveStudy. Journal of FamilyViolence, 16 (3), 255-268.

Hart, S. N.,Germain, R. B., \&Brassard, M. R. (1987). The Challenge: ToBetterUnderstandand Combat PsychologicalMaltreatment of ChildrenandYouth. PsychologicalMaltreatment of ChildrenandYouth, 3-24.

Hoffman, K. L.,Kiecolt, K. J., \&Edwards, J. N. (2005). PhysicalViolenceBetweenSiblings A TheoreticalandEmpirical Analysis. Journal of FamilyIssues, 26(8), 1103-1130.

Hughes, H. M., Parkinson, D., \&Vargo, M. (1989). WitnessingSpouseAbuseAndExperiencingPhysicalAbuse: "DoubleWhammy"?. Journal Of FamilyViolence, 4 (2), 197-209.

Irwin, A. R.,\&Gross, A. M. (1995). Cognitive Tempo, Violent Video Games, AndAggressiveBehavior İn YoungBoys. Journal of FamilyViolence, 10(3), 337-350.

Jouriles, E. N.,Barling, J., \&O'Leary, K. D. (1987). Predicting Child BehaviorProblems İn MaritallyViolentFamilies. Journal of Abnormal Child Psychology,15(2), 165-173.

Khan, R.,\&Cooke, D. J. (2013). Measurement of SiblingViolence A Two-Factor Model of Severity. CriminalJusticeandBehavior, 40(1), 26-39.

Kiselica, M. S.,\&Morrill-Richards, M. (2007). SiblingMaltreatment: TheForgottenAbuse. Journal of Counseling \& Development, 85 (2), 148-160.

Krienert, J. L.,\&Walsh, J. A. (2011). My Brother'sKeeper: A ContemporaryExamination of ReportedSiblingViolence Using National Level Data, 2000-2005. Journal of FamilyViolence, 26(5), 331-342.

Lewis, D. O. (2005). AdultAntisocialBehavior, CriminalityandViolence. Kaplan \&Sadock'sComprehensiveTextbook of Psychiatry, 8th Edition (Eds BJ Sadock, VA Sadock), 2258-2272.

Martin Del Campo, M. (2012). 'Creation and Validation of theSiblingAbuseScale',Faculty of San Diego StateUniversity, Master of Arts İn Psychology,San Diego.

Meyers, A. (2014). A Call to Child Welfare: ProtectChildrenfromSiblingAbuse. QualitativeSocialWork, 13(5), 654-670.

Morrill, M.,\&Bachman, C. (2013). ConfrontingTheGenderMyth: An Exploration of Variance in Male VersusFemaleExperienceWithSiblingAbuse. Journal of InterpersonalViolence, 28(8), 1693-1708.

Noller, P. (2005). SiblingRelationships in Adolescence: Learning andGrowingTogether. PersonalRelationships, 12(1), 1-22. 
Orue, I.,Bushman, B., Calvete, E., Thomaes, S., De Castro, B. O., \&Hutteman, R. (2011). MonkeySee, Monkey Do, Monkey Hurt: LongitudinalEffects Of ExposuretoViolence on Children'sAggressiveBehavior. Journal of SocialandPersonalRelationships, 2 (4), 432-437.

Skinner, J. A.,\&Kowalski, R. M. (2013). Profiles of SiblingBullying. Journal of InterpersonalViolence, 28(8), 1726-1736.

Steinmetz, S. (1981). A Cross-CulturalComparison of SiblingViolence. International Journal Of FamilyPsychiatry, 2, 337-351.

Suh, E. K.,\&Abel, E. M. (1990). TheImpact of SpousalViolence on theChildren of theAbused. Journal of IndependentSocialWork, 4 (4), 27-34.

Szasz, S. (1984). Sisters, Brothers, andOthers, W.W. Norton, Newyork.

Tippett, N.,\&Wolke, D. (2015). AggressionBetweenSiblings: Associationswiththe Home Environment and Peer Bullying. AggressiveBehavior, 41(1), 14-24.

Whipple, E. E.,\&Finton, M. S. E. (1995). PsychologicalMaltreatmentBySiblings: An Unrecognized Form of Abuse. Child andAdolescentSocialWorkJournal, 12 (2), 135146.

Wiehe, V. R. (1997). SiblingAbuse: HiddenPhysical, Emotional, andSexualTrauma. Sage Publications. 